\title{
Resisting stigma, embracing solidarity: An ethnographic study of shopaholics anonymous
}

\author{
Rachel Demerling
}

\begin{abstract}
In recent years, an increased interest in the phenomenon of compulsive buying, which is better known as "shopaholism", has occurred. This behaviour has been conceptualized as being an uncontrollable urge to purchase things which is pleasurable for an individual or relieves their distress and which results in negative consequences for that individual. This article examines the experiences of individuals within a Shopaholics Anonymous group to understand why individuals decide to join a support group and explore the dynamics of interaction among participants and how that shapes the outcome of their addiction.
\end{abstract}

Key words: compulsive buying; stigma; solidarity; addiction

Please cite this article as:

Demerling, R. (2011). Resisting stigma, embracing solidarity: An ethnographic study of shopaholics anonymous. Qualitative Studies, 2(1): 1-15.

\section{Introduction}

In recent years, an increased interest in the phenomenon of compulsive buying, which is better known as "shopaholism", has occurred. This behaviour has been conceptualized as being an uncontrollable urge to purchase things which is pleasurable for an individual or relieves their distress and which results in negative consequences for that individual (Dittmar, Long \& Bond, 2007; Faber \& O'Guinn, 1992; Frost \& Steketee, 2004). What is more, this phenomenon is attributed to being primarily a "female issue." This was prevalent in the 2008 film Confessions of a Shopaholic, where Rebecca Bloomwood is depicted as an adoring twenty-something year old whose quirks and charm make her shopping addiction funny and light hearted. Previous work on compulsive buying suggests that this behaviour stems from emotional difficulties and people engage in these behaviours to avoid feeling intense and unresolved emotions (Gallen, 2002). Thus, the question becomes, why do compulsive buyers join Shopaholics Anonymous and what do they gain from the group?

To explore this question, I studied a Shopaholics Anonymous group to uncover why individuals join support groups if they fear stigmatization. Does the group in fact help members improve their compulsive buying? A considerable amount of work has been done on psychological factors associated with compulsive buying; however, there is no work to date on compulsive buying support groups. This article examines the experiences of individuals within a Shopaholics Anonymous group to understand why individuals decide to join a support group and explore the dynamics of interaction among participants and how that shapes the outcome of their addiction.

\section{Literature Review}

Shopping as a Form of Compensation

Sociological literature on the topic of compulsive buying continues to be scant as compulsive buying is an issue, which is dominated by physiatrists and psychologists alike. Many attempts have been made to construct particular models, which can uncover and predict compulsive buying (Kellett \& Bolton, 2009; Ridgway, Kukar-Kinny \& Monroe, 2008; Kahler et al, 2008). Early developmental experiences and family upbringing have been associated with an 
increased attachment to belongings. It has been found that compulsive buyers report childhoods with a greater frequency of parents who used money and gifts as a means of positive reinforcement for desired behaviours, were less frequently encouraged as children to save and discouraged from expressing their opinions ( $\mathrm{O}^{\prime}$ Guinn and Faber, 1989). This form of upbringing can result in two causal processes. Firstly, it can lead to an over-emphasis regarding personal desirability and a distorted body image. Both of these traits require reinforcement of self-worth and self-esteem (DeSarbo \& Edwards, 1996). However, research shows that there is no significant correlation between happiness and money once household incomes are beyond $\$ 50,000$ per year (Chatzky, 2003; Easterbrook, 2005), but the immediacy of positive feelings pertains to the buying process rather than to the receiving or consumption of the product (Ridgway, Kukar-Kinney and Monroe, 2008). Although compulsive buying is not formally recognized as a mental disorder, it is being considered for inclusion in the fifth edition of the Diagnostic and Statistical Manual of Mental Disorders (DSM-V). There has been a surge of research signaling that this "habit" is not merely a lifestyle choice but an illness, comparable to gambling and alcoholism, which is a "persistent and recurrent maladaptive behaviour that disrupts personal, family or vocational pursuits" (American Psychiatric Association, 2000, p. 671). Thus, there is a strong body of evidence, which suggests that compulsive buyers develop the "habit" as a result of how they were socialized to view money. This perception has inevitably led such individuals to believe that money will provide personal fulfillment and satisfaction without detrimental long-term effects. However, this form of self-medication, once thought to be harmless, is slowly becoming viewed as a serious addiction worthy of medical treatment.

\section{Avoiding Stigma: Perpetual Myths about Shopaholics}

There are many beliefs about compulsive buying, which depict the essence of the disorder and at the same time perpetuate stereotypes. It is believed that buying objects will compensate, reward or neutralize negative feelings and that objects provide emotional security and emotional attachment. Moreover, it is believed that objects are unique with a marked opportunity cost should they not be purchased. Lastly, it is believed that compulsive buyers have a sense of heightened personal responsibility for objects (Kyrios et al., 2004). As a result of the negativity surrounding compulsive buying, many compulsive buyers experience shame, guilt and regret (O'Guinn and Faber, 1989). Thus, compulsive buyers try to conceal their behaviours to avoid stigma (Lee, Lennon, and Rudd, 2000). With that, many compulsive buyers have turned to the internet as a means of fulfilling their desires because they can shop and buy unobserved and avoid social interaction (Ridgway, Kinney, M, Monroe, 2008).

\section{"The Devil in Plastic": Detrimental Effects of Compulsive Buying}

Compulsive buying does not only affect the shopaholic, but is also a major source of conflict for couples and their families (Oggins, 2003). In a survey conducted of 1001 adults, more than half considered money to be a sensitive topic in their households. Forty percent surveyed reported that they had lied to their spouse about the cost of a purchase and forty percent expressed that they felt it was acceptable for their spouse not to share financial information with them (Medintz, 2004). Furthermore, research shows that disordered money behaviours have a significant negative impact on personal well-being. Being overly loose or tight with money, being overly concerned with financial success and being materialistic are all associated with lower ratings of well-being (Tatzel, 2002). In addition, financial problems have also been shown to negatively affect job performance. Research shows that adults who experience financial stress are less productive at work (Grensing-Pophal, 2002). Consequently, it is evident that compulsive buying is not an isolated act, but leads to a host of psychological, emotional and 
physical distress. What is more, since compulsive buying is negatively perceived, shopaholics feel unable to confront their family members and close friends about their disorder. Although the literature on disordered money behaviour provides ample information as to how compulsive buying begins and how it negatively affects individuals and their social networks, no literature to date has empirically studied shopaholic support groups. This is crucial in understanding the dynamics of the group to uncover how individuals decide to join a support group and what they gain from attending.

\section{Method}

The data used in this article were obtained through ethnographic research conducted over the course of four months (January-April 2010) in a Shopaholics Anonymous group in Southern Ontario. I attended and participated in the group on a weekly basis as well as conducted semistructured interviews with 7 of the 12 members, which were approximately one hour in duration. The reason I did not interview all of the members in the group is that some individuals simply did not feel comfortable talking about their struggles with compulsive buying in greater depth. The McMaster University research ethics board granted approval for this study and informed consent was obtained from individuals who participated in the semistructured in-depth interviews. All of the member's names were replaced with pseudonyms and all other identifiers were removed to ensure anonymity. When I attended the weekly meetings, I would sit in my car immediately following each meeting and write fieldnotes so my recollection of the meeting would be clearer. When I conducted the interviews, none of the participants felt comfortable being tape-recorded so I took notes during the interview and immediately after.

\section{Structure of Shopaholics Anonymous}

The Shopaholics Anonymous group I attended is a weekly support group where members come and share their experiences, struggles and successes with compulsive debting. The weekly meetings are hosted by a volunteer who took on the responsibility because the previous location of the meetings required that all members pay a fee for attending, so now the costs is free for all members. Every meeting begins with members sharing their experiences of the past week, which helps the group gauge how each member is progressing from week to week. Following that, a volunteer is selected to read a passage from the literature "A Currency of Hope." Each story is a personal narrative about how one came to be a compulsive debtor and the struggles they have incurred as a result. From that, members each take a turn discussing their relation to the theme of the passage. This portion of the meeting tends to be very emotional because it is the opportunity members have to delve into their past experiences and revive painful memories brought about by their struggle with compulsive debting. After each member has an opportunity to share their story, members then offer each other helpful tips as to how they can better manage their situation. It is obvious that individuals over time become emotionally invested in the lives of the other members and would like them to succeed in their ongoing struggles. However, to the best of my knowledge, none of the members have contact with one another outside of the meeting, as I heard no discussion of interaction or communication taking place beyond the weekly meetings. In the last portion of the meeting, members join hands and recite a prayer asking God to give them strength and guidance so they may on remain on the path to ridding their addiction.

This support group is advertised in local newspapers and welcomes any individuals who wish to control their compulsive buying. To be a member of this group there are a number of expectations that are placed on newcomers. Members are expected to stop incurring any 
unsecured debt beyond what they have already incurred. Members are expected to attend the meetings on a weekly basis and before deciding if the group is suitable to their needs, members are told to attend at least six meetings before making a decision. The group encourages members to record their expenses and income. It is strongly suggested that everyone carry a notebook and throughout the day write down everything they spend and any income they receive. Members are also encouraged to read the literature provided in the group, which includes A Currency of Hope, Alcoholics Anonymous, Twelve Steps and Twelve Traditions of Alcoholics Anonymous. Lastly, all members are expected to follow the twelve steps prescribed in the exact order of prescription.

In this Shopaholics Anonymous group, compulsive debting is referred to as a disease that never gets better, only worse as time passes. They argue that this disease, which is progressive in nature, can never be cured but only managed. This Shopaholics Anonymous group is comparable to Alcoholics Anonymous in that they follow a twelve steps program. The first step is admitting powerlessness over debt in that life has become unmanageable. The second step is to believe that a power greater than oneself can bring restoration of sanity. The third step is making a decision to turn your will and your life over to the care of God. The fourth step is making a fearless moral inventory of yourself. The fifth step is admitting to God, to yourself and to another human being the exact nature of your wrongs. The sixth step is being entirely ready to have God remove all defects of character. The seventh step is humbling asking God to remove your shortcomings. The eighth step is making a list of all persons you have harmed and be willing to make amends to them all. The ninth step is making a direct amends to such people wherever possible, except when to do so would injure them or others. The tenth step is continuing to take personal inventory and when you were wrong to promptly admit it. The eleventh step is to seek prayer and meditation to improve your conscious contact with God and praying only for knowledge and will. The twelfth and final step is to have a spiritual awakening as the result of the previous steps and to try and carry out this message to other compulsive debtors and to practice these principles in all your affairs.

\section{Review of Findings}

"Hi My Name is... and I'm a Shopaholic." Reasons for joining Shopaholics Anonymous

None of the members in this Shopaholics Anonymous group attend this support group for financial advice. The group acts as a moral support system and a safe environment for people to discuss their issues free of judgment. All of the members of the group joined Shopaholics Anonymous because they needed to discuss their financial woes and felt as though they could not do so with any close family or friends. Joan, a 53-year-old social worker and mother of two daughters explains her reasons for joining the shopaholics support group:

My debt just kept accumulating every single day and I was unable to face the music myself. I would try and ignore the problem but it's kinda hard when creditors are calling you several times a day. I felt trapped, like I had no one to turn to. I felt like everyone who knew about my debt was judging me, and at the same time I was not willing to share my problems with my close friends or family because I knew they would be critical. So one day I was surfing on the web and typed a bunch of key phrases with the word debt in them and all of a sudden this support group popped up. At first I dismissed the possibility of attending the meetings, but I honestly felt like a bottle of pop that has been shaken far too much and is going to burst any second. I needed to go somewhere I could talk about my issues and get relief. 
Similarly, Matthew, a 53- year- old computer analyst explains:

Well I got to a point in my life where my situation kept getting worse and worse and I had no one to talk to because I did not want anyone to find out. So one day, I was online searching for support and I found a meeting right near my house. I felt as if I was going to go insane if I did not talk to someone soon.

Matthew goes on to explain that joining the group made him feel a little bit better about his situation:

I know this sounds bad, but if your situation is so horrible, it makes you feel a little bit better knowing that someone else is in a horrible situation too. It is the only source of comfort you have at that point, to know that you're not the only one who can't control their money.

Attending the weekly support groups provides individuals with a sense of relief from the everyday stresses that their compulsive buying brings. All of the members feel a sense of entrapment because they are uncomfortable disclosing their issues to friends of family in fear of condemnation and disapproval. In addition, for all of the group members, especially Matthew, attending the meetings provides consolation because others share their struggle and they no longer feel completely isolated and alone.

The individuals in the Shopaholics Anonymous groups had very different reasons for compulsive buying and incurring insurmountable debt. For two of the individuals, their addiction to shopping did not occur until their mid-thirties when unfortunate life events took place. Joan describes how her compulsive buying began with the onset of her divorce. As a single mother of two kids, Joan said that she began incurring debt because she could not keep pace with the demands of providing for her children. However, although her children are grown, she has not been able to get out of debt because she does not know anything else. She said, "I get so much pleasure out of buying even a pencil. When I'm buying something, anything, I feel in control and happy." Joan feels like a lot of the issues she faced in childhood resurfaced in her adolescence and shopping has been the way she has suppressed those unresolved insecurities. Similarly, Melanie, a 44-year-old clerical assistant and mother of three children, explained how her history of compulsive spending began after she got divorced more than 10 years ago. After she paid her legal fees and split her assets with her ex-husband, Melanie became depressed and started compulsively shopping as a form of self-medication. Over the years, her spending caused her to max out all of her credit cards, which forced her to borrow money from friends and family to pay some of her monthly bills.

Unlike Joan and Melanie, Joe, a 42-year-old self-employed tradesman, began to incur debt because of the nature of his work and the irregular income that follows. Joe said that it is the nature of his work that caused his debt to skyrocket. Since he is self-employed, he always used credit cards to pay absolutely everything because sometimes he would not have the money in his account to pay for the purchase and other times, he would have the money but not want to use it in fear that he may not have a large pay check the following week. Thus, before he knew it, his debt kept accumulating and he never took the time to figure out a re-payment plan and just waited until it became too much to ignore. 
For the rest of the group members, compulsive buying began as a result of personal interests and hobbies that turned into obsessions. Matthew said that his debt occurred because he developed an obsession with films. This obsession would not only take the form of renting movies and going to the theatre much too often, but he would also spend days traveling to and staying over in Toronto to see TIFF films. Moreover, Matthew also began paying off credit cards with other credit cards and never properly dealt with his debt until a few years ago. In like manner, for Michael, a 44-year-old mechanic, debt accumulation began when he began fixing up cars and collecting them. As a mechanic, Michael is around cars everyday and so he began taking old cars and fixing them, which turned into a hobby. However, Michael began spending large amounts of money on car accessories, which accumulated into debt in the thousands: "At first, it was like ok I'll do this once and that will be it. But then you become good at it and before you know it you start buying special rims, tires and spoilers that cost a fortune."

Contrary to the literature on the development of compulsive buying, for all of the individuals in the group, compulsive buying did not begin or fully escalate until they reached middle age. For most, it was brought on by unfortunate life events, which either caused an emotional strain that led them down the path to compulsive buying or a financial strain, which led to the accumulation of massive debt. For a small minority in the group, it was the development of an interest or hobby, which demands excessive amounts of money to maintain that caused the incurrence of debt.

Unresolved Issues, Growing Debt

For the majority of individuals, their compulsive spending continued as a result of unresolved issues that were either mentioned or not. Many individuals had not resolved issues of insecurity, pain, or neglect and as a result have been unable, until now, to come to terms with their addictions. Moreover, many of the members had begun hiding their addictions from friends and family, which only served to worsen their problem because they were unable to openly talk about it and find a resolution. Joe said that for a few years, he did not discuss their financial situation with his wife because it made him feel like he was not a good provider for his family and because he did not want to upset his wife and cause martial strain. However, this secrecy only delayed the road to recovery for Joe because he kept spending the same so his wife would not notice there was a problem. He said:

I mean I didn't want to admit to Amy that we weren't doing well financially because what does that say about me? I don't want her thinking that she should have married someone else and that I can't support my own family. It has got to be the worst feeling, knowing that you can't adequately provide financially for your wife and kids. So basically I tried to avoid thinking about it as much as possible because it made me feel horrible. I guess I somehow figured that if I ignored the issue and didn't tell my wife, things would get better or at least go away.

Similarly, Joan said that for years she did not share her financial troubles with friends or family because as a single mother, she already felt stigmatized by her situation. Thus, Joan did not want people to think that not only can she not keep her personal life together, but she also cannot keep her finances in check. "After I got divorced, I had the stigma of a single parent, so for people to think I can't control my shopping, I was worried they would believe that was the reason my marriage fell apart." Lastly, Matthew expressed how he hid his debt from his parents for many years because he was too ashamed for them to find out. He always felt guilty that he could not afford to buy his parents nice gifts or take them on trips and always made his parents 
believe that he was just careful with his spending: "I was too afraid of what my parents would think of me. I mean I am not married and have no kids, so if I dropped this bomb on them, I was worried they would think I can't do anything right." For all of the members, what began as a relatively small issue grew uncontrollably because they did not confront the matter. Fear of stigma and disappointment from others hindered these individuals from disclosing their struggles with their close family and friends and so they found ways to conceal their addictions, which only served to worsen their financial situation.

\section{Techniques for Concealing Addiction}

Over time, the participants in this group developed different techniques to conceal their addiction from their family and friends. As a single mother, Melanie has always worked hard to hide her financial situation from her children. Although they are often refused many items they ask for, her children do not suspect their mother has any financial troubles. There has been a time Melanie has thought about telling her children about the situation, but she feared it would upset them, making them feel insecure. However, one time when her daughter was in the sixth grade, her class was going on a year-end trip to camp. The total cost for this trip was around $\$ 60$ and Melanie did not have enough money at the end of the week. So what she began to do is tell her daughter that the trip will not be any fun and that bugs will eat her. "I told Kelly, why do you want to go there anyway? You will get tons of mosquito bites and get really dirty. Besides we'll plan something better for the summer" After a few days, Kelly began to believe her mother and eventually decided not to attend the trip. However, all summer her daughter asked where they were going and Melanie had to pretend that she could not get the time off work to go on the trip she promised to take her daughter on.

When Michael first began accumulating debt, he ignored it and continued to live as usual. He always thought he would be able to take care of his debt and so he never let it dictate his life. Since Michael is unmarried, he was used to a life where he and his friends would be found at the bar on the weekends and would frequently take trips. Many of Michel's friends have wellpaying jobs, so Michael never felt comfortable talking about his financial problems. However, it got to the point one day where his debt became too much to ignore. He had agencies calling all the time and his credit cards were fully maxed out. Around that time Michael's friends were planning a trip to Mexico and he knew that if he declined, everyone would question him. To avoid that predicament, Michael asked his parents to borrow $\$ 2,000$. His parents were surprised at the request and began speculating. Michael told them the money was to help out a friend and that it would be repaid immediately. Months later, Michael was still unable to repay his parents and so he was forced to admit his situation. Michael felt this was the better option opposed to telling his friends he was in debt. Thus for Michael, he had to make the choice of either admitting his financial troubles to his family or friends and chose his family because they were the ones who lent him the money for which he could not repay.

Joan described her struggle to hide her financial troubles with her family for years. "Since I got divorced, everyone always tried to get information out of me. I guess they want to know all of the reasons why I got divorced or something." She said that she knew people always speculated about her finances because she lives in a run-down apartment and has an older car. Because of those perceptions, Joan would purposely buy new clothes whenever she was invited to a family function because she wanted to appear as though she was doing fine. She would also buy her family members elaborate gifts for Christmas and birthdays because they would tell her not to since they assumed she could not afford it, and so that would only cause her to buy more elaborate gifts. "Deep down I knew people knew about my situation and that I didn't have a lot 
of money. So to make myself and others believe I was doing fine, I would put on this big charade to show them they're wrong."

Lastly, Joe began talking about his experience with trying to hide his financial situation from his wife because he was afraid that if she knew the depth of their situation, she would leave him. Before Joe got married, his wife knew he did not have a lot of money, but Joe never actually came out and disclosed every aspect of his finances. He simply assured his wife that if she married him everything would turn out fine. A few years into their marriage, Joe's business did not flourish the way he had hoped. Eventually his debt grew to be too much. However, to show his wife everything was fine, Joe continued buying her flowers, taking her to restaurants and buying her nice gifts. This worked for a little while until creditors began calling his home and his wife found out. He was fearful that she would leave, but instead she began helping him devise a plan as to how they can get themselves out of this. She actually admitted to Joe that she suspected this problem for a few years, but tried to make herself believe it wasn't happening. For that reason, she also assumed part of the blame. Over time, all of the members had come to develop techniques for concealing their compulsive buying and the debt that followed in an attempt to avoid a stigma or in some instances a double stigma. However, for many, by doing so, their financial situation only worsened because instead of facing their debt, they spent more money trying to convince others they did not have an addiction.

\section{Group Accountability}

During the semi-structured interviews I conducted with some of the members of the group, I asked them if they felt accountable to the other group members with respect to their financial decision-making. Anne, a 46-year-old insurance broker replied:

Yes, for sure. Every week everyone is taking time out of their busy schedules to be a part of the group. Many people have spouses and children and so I wouldn't want to be wasting anyone's time by not making an effort to get the most I can out of the meetings. I want to come back every week and have something good to say about what I did to improve the situation. Besides, that motivates others to do their best too.

Just like Anne, Matthew also feels accountable to the other members which is the guiding force behind his motivation do the best he can each week:

Every week when we come back and share how our week has been, you definitely want to have something good to say. Sometimes I have the temptation to splurge and then I think that come Sunday, I don't want to tell everyone that, especially if the others have had a good week. Also, you begin to know which members are not doing that well and which ones need more motivation and so by sharing your positive experiences, you only hope that you are inspiring the weaker members of the group to change their situation.

Lastly, Melanie also echoes the notion of group accountability. She says: "We all owe it to each other to do the best we can each day to improve our situation. That's the point of the group. We are all in this together and are all here for the same reason. So it would be selfish for someone not to take this seriously." Consequently, all of the members feel accountable to the other participants to strive to improve their financial situation for the sake of the group. 


\section{Unwritten Rules/Codes of Behaviour}

Within Shopaholics Anonymous, there are certain unwritten rules and codes of behaviour, which all members are to abide by. Joan explains, "I think the most important thing is to never come off as judgmental because that is the whole point of the group. You never want to make someone feel bad about their situation, even if it is far worse than yours." She goes on to stress that "we all have bad days and bad weeks, so if someone does something stupid or careless, you shouldn't say anything negative. Our only role is to be supportive." Joan also explains that all the members try not to get really personal with one another because it would not be proper to start asking people private details such as how much debt they have or what they spend their money on. Matthew also echoes the inappropriateness of prying in the lives of the other members:

If someone wants to tell you something, they will. We're not here to get into everyone's business; it's merely a support system. I think also, you don't want to ever make your situation seem better than everyone else's. I know this sounds strange, but I don't consider my situation to be as bad as some of the others in the group because like I said, I'm a single guy. I don't have a family to support. But I'm not gonna ever insinuate that because that's not why I'm here.

Joe stresses the issue of criticism and how members of the group should resist passing judgment, regardless of the situation:

Well you also should never point out faults in anyone else or criticize them. If someone says something that is really ridiculous or surprising, you shouldn't ever point it out or make them feel bad. There are times when you hear someone say that they lost control and went to the casino one night and everyone's thinking, you have kids and wife, why are you clearly putting them last. But you can't say that, you just have to be supportive. After all, who am I to judge them? No matter how stupid I think someone is being, at the end of the day, we're all here for the same reason.

Evidently, all members agree that there are unwritten rules and codes of behaviour that everyone should abide by. Although there is no formal enforcement of such rules and codes of behaviour, every member is expected to be supportive of the other members and that entails not passing judgment or criticizing anyone for their actions or thoughts. The goal of the group is to provide ongoing support for individuals with compulsive buying. Thus it is inappropriate to pry into people's personal issues unless they willingly divulge that information.

\section{Shopaholics Anonymous: Is there a Financial Benefit?}

All of the participants in the group agree that with respect to their financial situations, attending the meetings made them become more accountable for their actions, which encouraged them to improve their overall situation. Jeremy, a 48-year-old steel worker explains:

Well yes, in the sense that I feel an obligation to them as a member of the group to make every effort to try and improve my situation. We are all cheering each other on every week. I like to attend the meetings having something positive to say. So I guess, in that sense, joining the group has made me more accountable for my actions in a way that I have not experienced before. 
In like terms, Michael says, "when you hear some of the positive steps others are taking to improve their finances, it sort of motivates you to want to get things right with your own situation. You know, if Joe is saying that he has paid down one of his credit cards, it makes others in the group feel like they'd better get the ball rolling and do something." Moreover, Matthew also agrees that attending the group has improved his financial situation in the sense that he does not ignore his situation anymore because the meetings are a constant reminder that he needs to work continuously to improve his finances:

Well, it's not like I get any sound financial advice. Let's be honest, I'm coming for support. I wouldn't exactly take financial advice from people who also can't control their own money. It's just emotional support. It makes you feel like your doing something to help your situation. Like you're on a path to finding a solution, even if you haven't really done anything at all. Just knowing that others share your personal struggle makes you feel like you can do something about it and it's not totally hopeless. For me, the meetings are what keep me in check. Before, I joined, weeks and months would go by and I would not really think about my problem or do anything about it. I would put my credit card bills in a hiding spot so I would forget about them. You know, out of sight, out of mind. But since joining the group, it forces me to constantly think about my finances, I don't ignore the problem anymore.

Thus, although Shopaholics Anonymous is not allowed to provide members with financial advice as to how they can better manage their finances, simply attending the meetings has had a considerable effect on the finances of members. Attending the meetings each week forces participants to face their problems instead of ignoring them and hoping they will disappear like in the past. The meetings give individuals the support, strength and motivation they need to no longer feel like their situation is hopeless, but that they have the ability to improve their finances because they are not the only ones facing this ongoing struggle. Ultimately, for all of the members, emotional support was the missing link that was previously lacking to take matters into their own hands and stop self-loathing.

\section{Discussion of Findings}

Resisting Stigma

Goffman (1968) conceptualizes stigma as an "attribute that is deeply discrediting and that makes the person carrying it different from others and of a less desirable kind." Stigma is a socially constructed phenomenon where there is evidence of an attribute that makes a person different from others and contains terms of undesirable 'deeply discrediting' attributes that 'disqualify one from full social acceptance' and motivates efforts by the stigmatized individual to hide the mark when possible (Goffman, 1963). Moreover, Hayward \& Bright (1997) identifies stigma as the negative effect of a label, while Schlosberg (1993) suggests that it is the establishment of deviant identities. Lastly, Corrigan \& Penn (1999) contend that stigma is another term for prejudice based upon negative stereotyping. When individuals have been ascribed a deviant characteristic by means of a label, individuals can follow a deviation from social norms. Thus, it can be inferred that labeling is the prerequisite for the very existence of deviance that justifies stigmatization.

Research shows that individuals with addictions are aware of the stereotypes that are associated with individuals in their group which causes them to resist mental illness labels and treatment altogether (Crocker \& Major, 1989; Owens, 2000; Hayward \& Bright, 1997). It is fear of social repercussions and condemnation that deter many addicts from seeking medical diagnosis and 
addiction treatment because they believe that admitting they have an addiction will equate to the internalization of such stereotypes. In addition, many addicts fear that if they admit to their addiction and are labeled mentally ill, their family members will receive a courtesy stigma (Goffman, 1963). A study conducted by Phlean, Bromet and Link (1998) found that the stigma family members receive is just as severe as the one placed on the mentally ill and is much greater than it has been in the past twenty years.

While conducting ethnographic research in Shopaholics Anonymous, it became increasingly prevalent that members joined the support group as a means of resisting stigmatization by their family and friends. Deciding to join Shopaholics Anonymous was a concerted effort to preserve their financial struggles from those close to them. Many of the individuals such as Joan and Matthew felt as though others already stigmatized them because of previous life events such as getting divorced or being unmarried and thus, essentially wanted to avoid a "double stigma" by concealing their compulsive buying. There is a growing body of research (Philo, 1996; Byrne, 1997) that supports the concept of stereotypes in mental illness that makes it easier for society to dismiss people and in doing so causes individuals to maintain their social distance. All of the members of Shopaholics Anonymous, weather previously stigmatized or not, joined the group because they felt unable to disclose their struggles of compulsive buying with their close friends and family. They fear disapproval and social condemnation that would result if members in their social circle gained knowledge about their poor financial state. As a result, for many, their financial situation worsened in the attempt to avoid disclosing their financial despair and keep up appearances. All of the members in the group went to great lengths to develop techniques to conceal their addiction. Members such as Joan and Joe continued buying friends and family elaborate gifts so that it would seemingly appear that their financial situation was fine. Other members would make up lies to close relatives to avoid disclosing information. Melanie make up lies to her children to avoid explaining her financial situation, and Matthew told his parents he needed to borrow money to help out a friend when it was for a vacation he did not want to decline.

It is apparent that all of the members in Shopaholics Anonymous joined the group as a means of resisting stigmatization. They needed an outlet to release the frustrations, anxieties and fears that they have been bottling up for so long. The group serves as a weekly "therapy" session where members can discuss both their successes and failures in battling their addiction without the risk of being labeled or stigmatized. Shopaholics Anonymous provides members with a safe environment to divulge personal information regarding their addiction to others who share their struggle and do not feel discredited or socially unaccepted. Thus, members do not join Shopaholics Anonymous to access financial information on money management as a means of improving their financial situation, but, rather, they join because the group provides them with the opportunity to discuss their personal struggles that they are unable to do so with their close family and friends.

\section{Embracing Solidarity}

Durkheim (1917) argued that religion acts as a source of solidarity and personal identification for individuals within society. Religion reinforces morals and social norms as well as provides social control, cohesion and meaning for individuals (Allen, Pickering \& Miller, 2008). Hogg, Adelman \& Blagg (2010) argue that religions are social groups that focus people's spiritual and existential curiosity and provide ideological and behavioural guidelines for this curiosity and everyday life. Studies show that people categorized as group members identify more strongly with their group when uncertainty is high (Grieve \& Hogg, 1999; Marigold, McGregor \& Kanna, 
2010). The rationale for strong group identification is that it reduces uncertainty because it solidifies a sense of self, how one should behave and how others will react. Thus a clearly structured group with clear boundaries, internal homogeneity, common goals, social interaction and unambiguous membership criteria creates a stronger sense of solidarity and reduces selfuncertainty (Grieve \& Hong, 1999).

Within the literature on mental health and addiction, research shows that participation in addiction support groups leads to an improvement in addiction outcome. Many studies have found that participation in AA is related to improvements in alcohol use (Humphreys, Moos, \& Cohen, 1997; 1998; Timko et al, 2005). A study conducted by Humphreys et al. (1997) found that among 628 previously untreated alcoholics, the number of AA meetings attended in the first three years following treatment predicted higher quality relationships, which in turn positively impacted one's progression in the program. Moreover, Timko et al. (2005) found that the duration of AA attendance significantly predicted an increase in friend resources in the support group.

Within Shopaholics Anonymous, practices of solidarity are not only exhibited, but are fully embraced by all members. Group accountability is a major theme that emerged during both participant observation and interviews. Members such as Anne and Matthew stressed group accountability because they feel that they owe it to the other members to do the best they can each week in terms of managing their finances, because all of the members are taking the time out of their busy schedules to attend the weekly meetings. Thus, every time they have the temptation to splurge on something unnecessary, they think of the group and the dedication everyone has and that deters them from deviating from their financial plan. Also, group members feel that their role is to help motivate and inspire the other members who are weaker. It is their obligation to ensure that everyone is reaching their full potential. Moreover, the notion of solidarity is also present when group members discuss the unwritten rules and codes of behaviour. Joe and Joan highlighted the fact that all members are expected to be a pillar of support, which includes never criticizing, or passing judgment on other members. Even if a group member makes a horrible financial decision, it is an unwritten rule that the other members are not warranted in condemning that individual. Their only role is to be supportive and provide endless encouragement. Furthermore, the theme of solidarity also emerged when group members discussed the financial benefits they receive from attending Shopaholics Anonymous. Michael and Matthew were among the many who emphasized that they do not receive any sound financial advice from attending the meetings nor did any of them join the group for that particular reason. The primary reason every member joined the group was for support and guidance from those who are experiencing the same struggles. All of the members stressed the fact that they take comfort in knowing that they are not alone in battling their addiction, which provides them with a sense of hope that they can improve their finances.

It is evident that all of the members in Shopaholics Anonymous joined the group to gain a sense of solidarity that is lacking in their everyday lives. What is more, the solidarity exhibited in this group is especially striking because of the accountability members have to one another. They feel a moral obligation to do their best each week to improve their financial situation because everyone is taking the time to attend the meetings each week. Moreover, members also feel obliged to inspire and encourage one other and to refrain from any criticism, which is evident in the unwritten rules and codes of behaviour. Additionally, this group mimics the structure religion provides because it gives members security, hope and solidarity. With that, it lowers people's sense of uncertainty and provides comfort in the face of financial hardship. 


\section{Conclusion}

In view of the fact that all of the members in this study feel unable to disclose their personal struggles with their close friends and family, they joined Shopaholics Anonymous as a means of resisting stigmatization and embracing solidarity. Given the stereotypes that exist about shopaholics, participants in this group feel unable to discuss their addiction with anyone because they fear being stigmatized. With that, their inability to express their financial problems leaves many participants feeling completely isolated and unsupported. These feelings proved to be a vicious cycle because isolation caused participants to fall further into debt because they virtually repressed their feelings of despair through compulsive buying and ignoring the matter altogether. Thus, while Shopaholics Anonymous does not provide financial education, advice or services to members, it serves as a religious institution providing support, encouragement and accountability, which in turn have proven to positively impact the financial situation of all members. The group provides stability, consistency and emotional security, which is something that is lacking in the lives of compulsive buyers. The mere fact of knowing that others share their struggle provides members with a sense of hope and encouragement to overcome their insurmountable debt. With that, the nature of the group is less about financial management and more about emotional support. Given the stigma surrounding compulsive buying, the importance of this support group is ever-present because individuals will ultimately avoid seeking help because they do not want to be labeled mentally ill. Thus, Shopaholics Anonymous has become a form of non-medical treatment because it is provides emotional support without labeling.

\section{References}

Allen. N.J., Pickering, W.S., Miller. W. 2008. On Elementary Forms of Religious Life. Routledge: UK.

American Psychiatric Association. 2000. Diagnostic and Statistical Manual of Mental Disorders ( $4^{\text {th }}$ ed; text revision).

American Psychological Association. 2004. "As tax deadline approaches." Americans say money is number one cause of stress. Retrieved March 1, 2010 from “http://www.apa.org/releases/moneystress.htm

Bryne, P. 1997. "Psychiatric stigma: past, passing and to come." Journal of the Royal Society of Medicine, 90, 618-620.

Chatzky, J. 2003. “The 10 commandments of financial happiness." Money, 32, 113-125.

Corrigan, P. W. 1998. "The impact of stigma on severe mental illness." Cognitive and Behavioral Practice, 5, 201-222.

Corrigan, P.W \& Penn, D.L. 1999. “Lessons from social psychology on discrediting psychiatric stigma." American Psychologist 54, 765-776.

DeSarbo, N.S \& Edwards, E.A. 1996. "Typologies of compulsive buying behaviour: A constrained cluster-wise regression approach." Journal of Consumer Psychology 5, 231-262. 
Dittmar, H, Long, K, \& Bond, R. 2007. “When a better self is only a click away: Associations between materialistic values, emotional and identity-related buying motives and compulsive buying online. Journal of Social and Clinical Psychology, 26, 334-366.

Easterbrook, G. 2005. “The real truth about money.” Time, 165, 32-34.

Faber, R and O'Guinn, T. 1992. "A clinical screener for compulsive buying." Journal of Consumer Research, 19, 459-479.

Frost, R.O, Steketee, G, \& Williams, L.F. 2002. "Compulsive buying, compulsive hoarding and obsessive compulsive hoarding." Behaviour Research and Therapy 34, 341-350.

Gallen, R. 2002. The money trap: A practical program to stop self-defeating financial habits so you can reclaim your grip on life. New York: The New York American Library, Inc.

Goffman, E. 1963. Stigma: Notes on the Management of Spoiled Identity. Penguin Books, London.

Goffman, E. 1968. Stigma: Notes on the Management of Spoiled Identity. Penguin Books, London.

Grensing-Pophal, L. 2002. “Drowning in debt.” Credit Union Management 25, 42-45.

Grieve, P., \& Hogg, M. A. (1999). “Subjective uncertainty and inter- group discrimination in the minimal group situation." Personality and Social Psychology Bulletin, 25, 926-940.

Hayward, P, \& Bright, J. 1997. "Stigma \& mental illness: a review and critique." Journal of Mental Health, 6, 345-354.

Hogg, M., Adelman, J., Blagg, R. 2010. "Religion in the Face of Uncertainty: An Uncertainty Identity Theory Account of Religiousness." Personality and Social Psychology Review, 14(1) 72-83.

Humphreys, K., Moos, R., \& Cohen, C. 1997. "Social and community resources and long-term recovery from treated and untreated alcoholism." Journal of Studies on Alcohol, 58, 231-238.

Kahler et al. 2009. "Personality, psychiatric disorders and smoking in middle-aged adults." Nicotine and Tobacco Research, 11(7), 833-841.

Kellet, S \& Bolton, J. 2009. "Compulsive buying: A cognitive behavioural model." Clinical Psychology and Psychotherapy, 16(2), 83-99.

Kyrios, M \& Frost, R.O, \& Steketee, G. 2004. "Cognitions in compulsive buying and acquisition." Cognitive Therapy \& Research 28, 241-258.

Lee, S., Lennon, S., Rudd, N. 2000. "Compulsive consumption tendencies among television shoppers." Family and Consumer Sciences Research Journal, 28(4), 463-489.

Marigold, D. C., McGregor, I., \& Zanna, M. P. (2010). Defensive conviction as emotion regulation: Goal mechanisms and interpersonal implications. In R. M. Arkin, K. C. Oleson, \& P. J. Carroll (Eds.), Handbook of the uncertain self. New York: Psychology Press. 
Medintz, S. 2004. "Secrets, lies and money." Money, 34, 121-128.

Oggins, J. 2003. "Topics of marital disagreement among African-American and Euro American newlyweds." Psychological Reports 92, 417-433.

O'Guinn, T, and Faber, R. 1989. “Compulsive buying: A phenomenological exploration.” Journal of Consumer Research 16, 147-165.

Phelan, J. C., Bromet, E. J., \& Link, B. G. 1998. "Psychiatric illness and family stigma." Schizophrenia Bulletin, 24, 115-126.

Philo, G. 1996. Media and Mental Distress. Addison Wesley Longman, New York.

Ridgway, N, Kukar-Kinney, M, Monroe, K. 2008. "An expanded conceptualization and a new measure of compulsive buying." Journal of Consumer Research 35(4), 622-639.

Schlosberg, A. 1993. "Psychiatric stigma and mental health professionals." Medicine and Law 12, 409-416.

Tatzel, M. 2002. "'Money Worlds' and well-being: As integration of money dispositions, materialism and price-related behaviour." Journal of Economic Psychology 23, 103-126.

Timko, C., Finney, J., \& Moos, R. 2005. “The 8-year course of alcohol abuse: Gender differences in social context and coping." Alcoholism, Clinical and Experimental Research, 29, 612-621.

\section{Author}

Rachel Demerling is a Ph.D. candidate in the Department of Sociology, McMaster University, studying sexuality, gender and inequality. Email: demerlr@univmail.cis.mcmaster.ca 